\title{
PNEUMOCOCCAL CARRIAGE RATE IN CHILDREN AND THEIR ANTIMICROBIAL SUSCEPTIBILITY PATTERNS IN AN URBAN SET UP
}

\author{
Nandan T. M, Jagadeesh, Anjana. G.
}

1. Senior Resident. Department of Neuromicrobiology, NIMHANS, Bangalore.

2. Professor. Department of Microbiology, KIMS, Bangalore.

3. Associate Professor. Department of Microbiology, KIMS, Bangalore.

\section{CORRESPONDING AUTHOR:}

Dr. Nandan. T. M,

Non PG Senior Resident,

Dept. of Neuromicrobiology,

NIMHANS, Bengaluru.

E-mail: drnandanv@yahoo.co.in

ABSTRACT: INTRODUCTION: S.pneumoniae is the major cause of morbidity and mortality in India and abroad and carriage is the key to invasive disease. Carriage (20-60\%) and invasive disease are more prevalent in children and in the elderly. Increased case fatality is due to the emergence of Penicillin and Multidrug Resistant S.pneumoniae worldwide. Penicillin has been the drug of choice for treatment of pneumococcal infections but the increasing number of reports of penicillin resistant pneumococci (PRP) throughout the world makes it essential to regionally determine the prevalence of PRP. MATERIALS AND METHODS: Nasopharyngeal swabs were collected from children between $\geq 3$ months and $\leq 5$ years of age attending paediatric immunization OPD in a medical college tertiary care hospital and research centre, Bengaluru, between December 2008 and August 2009 ( 8 months). S. pneumoniae were isolated based on colony morphology, Gram's staining, optochin sensitivity, and bile solubility. Antimicrobial susceptibility testing was carried out by Kriby-Bauer disc diffusion method for recommended commonly prescribed antibiotics. Oxacillin resistant strains denoting penicillin resistance were tested for Minimum inhibitory concentration for Penicillin G by Epsilometer test. RESULTS: 53 (27.89\%) S. pneumoniae were isolated from 190 nasopharyngeal swabs. 9 $(16.98 \%)$ isolates have been intermediately penicillin resistant by E test. Only 5 (9.43\%) and 34 $(64.15 \%)$ isolates were sensitive to co-trimoxazole and tetracycline respectively. 51 isolates were susceptible to cefotaxime, $48(90.56 \%)$ each were susceptible to erythromycin and ciprofloxacin. 25(47.19\%) out of 53 isolates could be recovered at the end of one year stored in STGG medium at $-20^{\circ} \mathrm{C}$. Serogroup types $19,10,3,14,7$, were common among the isolates. CONCLUSION: Carriage of S. pneumoniae is prevalent among young children in Bengaluru, which may predispose them to subsequent invasive pneumococcal diseases. There is decreased susceptibility to penicillin and other recommended antibiotics that may warrant appropriate culture and sensitivity testing during the management of invasive pneumococcal diseases and prescription of antibiotics in general.

KEY WORDS: Streptococcus pneumoniae, pneumococcal carriage, epsilometer test, penicillin resistant pneumococci

INTRODUCTION: S. pneumoniae is a major cause of morbidity and mortality in India and abroad and carriage is the key to invasive disease [1,2,3]. S. pneumoniae causes infections of the middle ear, sinuses, trachea, bronchi, and lungs by direct spread from the nasopharyngeal site of colonization. Infections of the CNS, heart valves, bones, joints, and peritoneal cavity usually arise 
by hematogenous spread; peritoneal infection also results from ascent via the fallopian tubes. The CNS may also be infected by contiguous spread of organisms, as in patients who have a tear in the dura. ${ }^{4,5]}$.

Carriage $(20-100 \%)$ is the key to invasive disease [6]. Carriage and invasive disease are more prevalent in children $[2,4,5]$. Increased case fatality is due to the emergence of Penicillin and Multidrug Resistant S. pneumoniae worldwide. Penicillin has been the drug of choice for treatment of pneumococcal infections but the increasing number of reports of penicillin resistant pneumococci (PRP) throughout the world makes it essential to determine the regional prevalence of PRP [3,7, 8]. Nasopharyngeal carriage of PRP in children also could reflect antimicrobial usage, with regard to both the individual and total antimicrobial consumption in the community ${ }^{[9,10]}$.

\section{Epidemiology of pneumococcal infections in children: Carriage [2]}

S. pneumoniae colonizes the nasopharynx and, on any single occasion, can be isolated from 20 to $100 \%$ of healthy children and 5 to $10 \%$ of healthy adults [5,11,12 ]. Once the organisms have colonized, they are likely to persist for 4 to 6 weeks but may persist for as long as 6 months. Rates of pneumococcal carriage peak during the first two years of life and decline gradually thereafter. Nasopharyngeal carriage of pneumococci is common among young children attending out-of-home care with rates of $21-59 \%$ in point prevalence estimates and $65 \%$ in longitudinal studies [13]. Defects in the mucosal immune response may contribute to these higher rates of carriage, but a more likely explanation is continued high exposure to pneumococci at all stages of life. Since the licensure of the 7 valent pneumococcal conjugate vaccine, the prevalence of carriage and infection with vaccine serotypes has declined and a shift to increased carriage or infections with non-vaccine serotypes has occurred [13].

Host predisposition: S. pneumoniae is the most frequent cause of bacteremia, bacterial pneumonia, and otitis media, and the second most common cause of meningitis in children. The decreased ability in children $<2 \mathrm{yr}$ of age to produce antibody against the $\mathrm{T}$ cell-independent polysaccharide antigens and the high prevalence of colonization may explain an increased effectiveness of polysaccharide vaccines. Males are more commonly affected than females. Other high risk groups include children with sickle cell disease, splenic dysfunction, HIV infection, cochlear implants, congenital immune deficiencies, cyanotic congenital heart disease, chronic pulmonary disease, cerebrospinal leaks, chronic renal insufficiency, immunosuppressive therapies, diabetes mellitus, etc., ${ }^{[13] .}$

Transmission: No significant animal reservoir of infection exists [14]. Pneumococci spread from one individual to another by direct or droplet transmission as a result of close contact; transmission may be enhanced by crowding or poor ventilation. Day-care centers have been a site of spread, especially of penicillin-resistant strains ${ }^{[7]}$.

\section{Objectives of the study:}

1. To determine the carriage percentage of $S$. pneumoniae in healthy children $\geq 3$ months and $\leq$ 5 years.

2. To study antimicrobial susceptibility patterns of $S$. pneumoniae isolates.

3. To determine Penicillin MIC for oxacillin resistant S. pneumoniae isolates. 
Methodology: Study was conducted in the department of microbiology in association with the department of pediatrics of a medical college tertiary care hospital and research centre in Bengaluru. The total duration of study was about 8 months between December 2008 and August 2009. The sample size was 190.

\section{Inclusion Criteria [2, 3]}

Children $\geq 3$ months to $\leq 5$ years old attending Pediatric OPD for routine childhood immunization.

\section{Exclusion Criteria [2, 3]:}

- Recent (3 months) hospitalization.

- Current antibiotic therapy.

- Current or recent invasive pneumococcal disease.

- Known immunologic disorders.

- Consent refusal.

Sample collection [1,15, 16]: Nasopharyngeal samples were taken with a nasopharyngeal swab ( $1 \mathrm{~mm}$, pediatric cotton tipped, from Hi Media Laboratories, Mumbai.) after consent of the parent/guardian. To obtain the specimen, the child's head was tipped slightly backward and the swab passed directly backwards, parallel to the floor of the nose. The swab should pass without resistance until it reaches the posterior pharynx which is approximately one-half to two-thirds the distance from the nostril to the ear lobe. If resistance was encountered, the swab was removed, and an attempt was made to pass the swab through the other nostril. Once the swab was in place, it was rotated 180 degrees or left in place for $5 \mathrm{~s}$ to saturate the tip before removing it slowly. The swabs were immediately streaked on to a $5 \%$ sheep blood agar plate [15]. Fig. 1.

Identification and characterization $[1,17]$ The plated 5\% sheep blood agar plates were incubated at $35-37^{\circ} \mathrm{C}$ in a $\mathrm{CO}_{2}$ jar (candle extinction jar) for $24 \mathrm{hr}$. Colonies typical of pneumococci $(\alpha$-lytic glistening draughtsman colonies) were selected and identified by Gram staining, optochin sensitivity (inhibition zone $\geq 14 \mathrm{~mm}^{[1]}$ ) and bile solubility.

Smears were made from a typical colony with a straight wire, air dried, and heat fixed. Figs. 2-4.

Antimicrobial susceptibility testing [1, 18, 19]: Antimicrobial susceptibility testing was carried out by Kirby Bauer disc diffusion method as per CLSI guidelines (formerly NCCLS) for penicillin, erythromycin, co-trimoxazole, and tetracycline. Penicillin susceptibility was tested using oxacillin $(1 \mu \mathrm{g})$ disc. For cefotaxime and ciprofloxacin, interpretations were done as for other hemolytic streptococci [1]. Fig. 5.

Penicillin Minimum Inhibitory Concentrations (MIC) for Oxacillin resistant (zones showing $\leq 19 \mathrm{~mm})[1,18,20] S$. pneumoniae were determined by E-test [4]. Control strain: Streptococcus pneumoniae ATCC 49618.

\section{E-test MIC parameters [1, 2, 21]:}

- MIC of $\leq 0.06 \mu \mathrm{g} / \mathrm{mL}$ was taken as penicillin susceptible pneumococci;

- MIC of 0.12-1 $\mu \mathrm{g} / \mathrm{mL}$ as penicillin intermediate resistant pneumococci and 
- $\quad$ MIC of $\geq 2 \mu \mathrm{g} / \mathrm{mL}$ as penicillin resistant pneumococci.

\section{RESULTS:}

- Streptococcus pneumoniae was isolated from 53 (27.89\%) of 190 samples, Graph 1.

- $\quad$ Nine (16.98\%) of $S$. pneumoniae isolated were found to be resistant to oxacillin and 44 (83.02\%) sensitive. Graph 2 shows the pediatric age distribution of pneumococcal carriage. Graph 3 shows the carriage of pneumococci in male and female children.Table 1 shows the antimicrobial resistance pattern of the isolates. Table 2 shows the antimicrobial susceptibility patterns of oxacillin resistant strains.

- Table 3 shows the antimicrobial susceptibility patterns of oxacillin sensitive strains. Graph 4 shows the distribution and the range of MICs of penicillin (of the oxacillin resistant strains) among the genders. Oxacillin resistance was more prevalent in the male population (6 versus 3 isolates). Table 4 shows the prevalence of overall multidrug resistance (MDR) and the prevalence of MDR strains among the oxacillin resistant and oxacillin sensitive strains. Ten (18.9\%) out of 53 isolates were resistant to at least three different classes of antibiotics. Five (55.6\%) of oxacillin resistant strains were resistant to at least 2 more classes and 5 (44\%) of oxacillin sensitive strains were resistant to at least 3 different classes of antibiotics. Serogroup types are listed in the Table 5 (Pending further analysis).

Table 1: Antimicrobial agent and number of resistant strains

\begin{tabular}{|l|l|l|l|}
\hline Antimicrobial agents & $\begin{array}{l}\text { Number of resistant strains } \\
(\mathbf{n = 5 3 )}\end{array}$ & $\mathbf{\%}$ & $\mathbf{9 5 \% C I}$ \\
\hline 1.OXACILLIN $(1 \mu \mathrm{g})$ & 9 & 16.9 & $9.20-29.23$ \\
\hline 2.ERYTHROMYCIN $(15 \mu \mathrm{g})$ & 5 & 9.4 & $4.10-20.25$ \\
\hline 3.COTRIMOXAZOLE $(25 \mu \mathrm{g})$ & 48 & 90.6 & $79.75-95.90$ \\
\hline 4.CEFOTAXIME $(30 \mu \mathrm{g})$ & 2 & 3.8 & $1.04-12.75$ \\
\hline 5.CIPROFLOXACIN $(5 \mu \mathrm{g})$ & 5 & 9.4 & $4.10-20.25$ \\
\hline 6.TETRACYCLINE $(30 \mu \mathrm{g})$ & 19 & 35.8 & $24.30-49.31$ \\
\hline
\end{tabular}

Table 2: Antimicrobial agent and number of resistant strains among 0xacillin resistant strains

\begin{tabular}{|l|l|l|l|}
\hline Antimicrobial agents & $\begin{array}{l}\text { Number of resistant strains } \\
(\mathbf{n = 9})\end{array}$ & $\mathbf{\%}$ & $\mathbf{9 5 \% C I}$ \\
\hline 1.ERYTHROMYCIN $(15 \mu \mathrm{g})$ & 2 & 22.2 & $6.32-54.74$ \\
\hline 2.COTRIMOXAZOLE $(25 \mu \mathrm{g})$ & 9 & 100.0 & $70.09-100.00$ \\
\hline 3.CEFOTAXIME $(30 \mu \mathrm{g})$ & 2 & 22.2 & $6.32-54.74$ \\
\hline 4.CIPROFLOXACIN $(5 \mu \mathrm{g})$ & 3 & 33.3 & $12.06-64.58$ \\
\hline 5.TETRACYCLINE $(30 \mu \mathrm{g})$ & 4 & 44.4 & $18.88-73.33$ \\
\hline
\end{tabular}


Table 3: Antimicrobial agent and number of resistant strains among Oxacillin sensitive strains

\begin{tabular}{|l|l|l|l|}
\hline Antimicrobial agents & $\begin{array}{l}\text { Number of Sensitive strains } \\
(\mathbf{n = 4 4 )}\end{array}$ & $\mathbf{\%}$ & $\mathbf{9 5 \% C I}$ \\
\hline 1.ERYTHROMYCIN $(15 \mu \mathrm{g})$ & 3 & 6.8 & $2.35-18.23$ \\
\hline 2.COTRIMOXAZOLE $(25 \mu \mathrm{g})$ & 38 & 86.4 & $73.29-93.80$ \\
\hline 3.CEFOTAXIME $(30 \mu \mathrm{g})$ & - & - & - \\
\hline 4.CIPROFLOXACIN $(5 \mu \mathrm{g})$ & 2 & 4.5 & $1.26-15.13$ \\
\hline 5.TETRACYCLINE $(30 \mu \mathrm{g})$ & 15 & 34.1 & $21.88-48.86$ \\
\hline
\end{tabular}

Table 4: Multidrug resistance

\begin{tabular}{|l|l|l|}
\hline Multidrug resistance & Number & $\mathbf{\%}$ \\
\hline Oxacillin resistant & $5 / 9$ & 55.6 \\
\hline Oxacillin Sensitive & $5 / 44$ & 11.4 \\
\hline Overall multi drug resistance & $10 / 53$ & 18.9 \\
\hline
\end{tabular}

Serogrouping: Serogrouping was performed for the viable isolates by: latex agglutination and the Neufeld quellung reaction. Kits were procured from Statens Serum Institut, Denmark. Both the methods were done by the checkerboard system. Serogroup types are listed in the Table 5, with pending further analysis.

Table 5.

\begin{tabular}{|l|l|l|l|}
\hline SEROGROUP type & NUMBER of isolates & SEROGROUP type & $\begin{array}{l}\text { NUMBER } \\
\text { isolates }\end{array}$ \\
\hline serogroup 19 & 5 & serogroup1 & 2 \\
\hline serogroup 10 & 3 & serogroup 6 & 1 \\
\hline serogroup 3 & 3 & serogroup 9 & 1 \\
\hline serogroup 14 & 3 & & \\
\hline serogroup 7 & 3 & & \\
\hline serogroup 18 & 2 & & 25 \\
\hline serogroup 11 & 2 & TOTAL & \\
\hline
\end{tabular}




\section{DISCUSSION}

\section{PNEUMOCOCCAL CARRIAGE}

The study population represented a typical urban set-up in India. Carriage of pneumococci among children $<5 \mathrm{yr}$ was found to be $27.9 \%$ that was higher than the average carriage rate (22.3\%) noted in the largest epidemiological study conducted by the ANSORP Study Group on the surveillance of pneumococcal resistance in Asia and the Middle East [2]. However, the Indiaspecific carriage rate recorded by the same study was higher $(43 \%)$, which was done in the Christian Medical College, Vellore [2]. This could be due to differences in the study population with respect to geographical area.

Age matched comparison with other studies.

Indian scenario

\begin{tabular}{|l|l|l|}
\hline Study & Place & Pneumococcal carriage rate \\
\hline Present & Bangalore & $27.9 \%(<5$ yr age group $)$ \\
\hline ANSORP (2001) [2] & Vellore & $43.2 \%(<5$ yr age group $)$ \\
\hline
\end{tabular}

International scenario

\begin{tabular}{|c|c|c|}
\hline Study & Country & $\begin{array}{l}\text { Pneumococcal carriage } \\
\text { rate }\end{array}$ \\
\hline $\begin{array}{l}\text { Huebner RE et.al (1998) [22 } \\
\text { ] }\end{array}$ & South Africa & $77 \%$ (<5 yr age group) \\
\hline ANSORP (2001) [2] & $\begin{array}{l}\text { Asia and Middle } \\
\text { East }\end{array}$ & $22.3 \%$ ( $<5$ yr age group) \\
\hline Samore MH (2001) [23] & Utah, USA & $24 \%(<8$ yr age group) \\
\hline Jie LJ et al. (2001) [24] & Beijing, China & $37.2 \%$ (<5 yr age group) \\
\hline Lo WT et al. (2003) [25] & Taiwan & $\begin{array}{l}20.83 \% \\
\text { group })\end{array}$ \\
\hline Saha SK et al. (2003) [26] & Bangladesh & $33 \%(<5$ yr age group $)$ \\
\hline Katsarolis et al (2009) [27 ] & Greece & $\begin{array}{llll}29.41 \% & (<5 & \text { yr } & \text { age } \\
\text { group }) & & & \end{array}$ \\
\hline $\begin{array}{l}\text { Kandakai YT et al. (2009) } \\
\text { [28] }\end{array}$ & Nigeria & 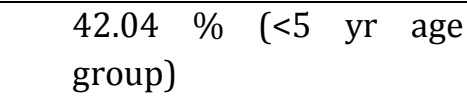 \\
\hline
\end{tabular}

Antimicrobial resistance pattern among carriage isolates.: Highest degree of resistance was found to co-trimoxazole (90.6\%), followed by penicillin (16.9\%), tetracycline (35.8\%), 
erythromycin and ciprofloxacin $(9.4 \%$ each), and the lowest degree to cefotaxime. This was in agreement with most of the studies.

Penicillin resistance. Analysis of the resistance patterns showed a higher rate of penicillin resistance (16.9\%) among the isolates, which is similar to a Nepali study (15.4\%), slightly above than that was noted by the ANSORP Study Group for the Indian strains (12.8\%), but well below than that of the Group's average of $35.8 \%$ in the Asian region.

The degree of susceptibility to penicillin among the colonizers was similar in both the studies i.e., all the strains were only intermediately resistant to penicillin [2]. Another study by the same group involving invasive isolates also recorded similar lower degree of resistance pattern to penicillin compared to the higher degree of resistance in other parts of the Asian region and therefore high grade penicillin resistance is not yet a problem in India [2]. But with the CLSI 2008 [29] correction for MIC of Penicillin for meningitis group of patients where in MIC of $0.1-1 \mu \mathrm{g} / \mathrm{mL}$ is considered 'resistant' to penicillin, it would be prudent to accept the prevalence of PRP in India. Moreover, studies done in the rest of the world have shown highgrade penicillin resistance patterns even according to the previous CLSI guidelines.

However, in the case of isolates those cause meningitis, even the penicillin intermediate resistance category fall into resistant group according to the CLSI-2008 guidelines. All the isolates in this study fall into resistant category in case they cause meningitis. But, if they cause invasive diseases other than meningitis, they will be considered sensitive. Comparison with other studies

Indian scenario

\begin{tabular}{|l|l|l|}
\hline Study & Place & Penicillin resistance rate \\
\hline Present & Bangalore & $16.9 \%$ \\
\hline ANSORP (2001) & Vellore & $12.8 \%$ \\
\hline
\end{tabular}

International scenario

\begin{tabular}{|l|l|l|}
\hline Study & Country & Penicillin resistance rate \\
\hline ANSORP (2001) & Sri Lanka & $76.5 \%$ \\
\hline Jie LJ et al. (2001) & Beijing, China & $8.2 \%$ \\
\hline Lo WT et al. (2003) & Taiwan & $89.5 \%$ \\
\hline Saha SK et al. (2003) & Bangladesh & $7 \%$ \\
\hline Sherchand JB et al (2008) [30] & Nepal & $15.4 \%$ \\
\hline Katsarolis et al (2009) & Greece & $48.9 \%$ \\
\hline Kandakai YT et al. (2009) & Nigeria & $29.7 \%$ \\
\hline
\end{tabular}

Antimicrobial resistance to other commonly used antibiotics. The antimicrobial susceptibility profiles for both penicillin - sensitive and resistant strains of S. pneumoniae were 
similar. Both exhibited varying degrees of resistance to several groups of antimicrobials. However, isolates found to be resistant to penicillin showed a higher degree of resistance to other antimicrobial agents. This agrees with reported findings that pneumococcal isolates resistant to penicillin are likely more resistant to macrolides, cephalosporins, tetracyclines, as well as some other antimicrobials.

Macrolide resistance: Erythromycin resistance rate among all the isolates was $9.4 \%$, higher than the Vellore rate and very much lower than the studies in other parts of the world.

Comparison with other studies

Indian scenario

\begin{tabular}{|l|l|l|}
\hline Study & Place & Erythromycin resistance rate \\
\hline Present & Bangalore & $9.4 \%$ \\
\hline ANSORP (2001) & Vellore & 0 \\
\hline
\end{tabular}

International scenario

\begin{tabular}{|l|l|l|}
\hline Study & Country & Erythromycin resistance rate \\
\hline ANSORP (2001) & Sri Lanka & $15.3 \%$ \\
\hline Jie LJ et al. (2001) & Beijing, China & $72 \%$ \\
\hline Lo WT et al. (2003) & Taiwan & $91.6 \%$ \\
\hline Saha SK et al. (2003) & Bangladesh & $2 \%$ \\
\hline Katsarolis et al (2009) & Greece & $66.8 \%$ \\
\hline Kandakai YT et al. (2009) & Nigeria & $32.43 \%$ \\
\hline
\end{tabular}

Co-trimoxazole resistance: Co-trimoxazole resistance rate was $90.6 \%$, the highest degree of resistance among all the antibiotics. This was similar to other studies in India and abroad and warns of treatment failures if it is continued to be used as the first cheapest and convenient option. Comparison with other studies

Indian scenario

\begin{tabular}{|l|l|l|}
\hline Study & Place & Co-trimoxazole resistance rate \\
\hline Present & Bangalore & $90.6 \%$ \\
\hline ANSORP (2001) & Vellore & $62.3 \%$ \\
\hline
\end{tabular}

International scenario

\begin{tabular}{|l|l|l|}
\hline Study & Country & Co-trimoxazole resistance rate \\
\hline ANSORP (2001) & Sri Lanka & $76.3 \%$ \\
\hline Jie LJ et al. (2001) & Beijing, China & $70 \%$ \\
\hline Lo WT et al. (2003) & Taiwan & $88.4 \%$ \\
\hline Saha SK et al. (2003) & Bangladesh & $77 \%$ \\
\hline Katsarolis et al (2009) & Greece & $69 \%$ \\
\hline
\end{tabular}

Tetracycline resistance: Tetracycline resistance rate among all the isolates was $35.8 \%$. This was similar to that was found by the ANSORP study for Vellore, but was lower than that found in many other studies. 
As the usage of tetracyclines in the pediatric age group is minimal, resistance to tetracycline is just a measure of MDR strains and a representative of pneumococcal antibiotic resistance in the community at large. Comparison with other studies

Indian scenario

\begin{tabular}{|l|l|l|}
\hline Study & Place & Tetracycline resistance rate \\
\hline Present & Bangalore & $35.8 \%$ \\
\hline ANSORP $(2001)$ & Vellore & $35.8 \%$ \\
\hline
\end{tabular}

International scenario

\begin{tabular}{|l|l|l|}
\hline Study & Country & Tetracycline resistance rate \\
\hline ANSORP (2001) & Sri Lanka & $47.9 \%$ \\
\hline Jie LJ et al. (2001) & Beijing, China & $79 \%$ \\
\hline Lo WT et al. (2003) & Taiwan & $88.4 \%$ \\
\hline Katsarolis et al (2009) & Greece & $51.1 \%$ \\
\hline Kandakai YT et al. (2009) & Nigeria & $27.02 \%$ \\
\hline
\end{tabular}

Extended spectrum cefalosporin resistance: Cefotaxime resistance rate among all the isolates was $3.8 \%$, which, fell into the oxacillin resistant group. This lower rate is similar to that found in majority of the studies but for few countries like Sri Lanka, for

which, the ANSORP study found a higher resistance rate. Increasing the dose, addition of vancomycin, Rifampin, appropriate use of microbiological facilities etc., is the current recommended solution. Comparison with other studies

Indian scenario

\begin{tabular}{|l|l|l|}
\hline Study & Place & Cefotaxime resistance rate \\
\hline Present & Bangalore & $3.8 \%$ \\
\hline ANSORP (2001) & Vellore & 0 \\
\hline
\end{tabular}

International scenario

\begin{tabular}{|l|l|l|}
\hline Study & Country & Cefotaxime resistance rate \\
\hline ANSORP (2001) & Sri Lanka & $23.5 \%$ \\
\hline Jie LJ et al. (2001) & Beijing, China & 0 \\
\hline Lo WT et al. (2003) & Taiwan & $8.4 \%$ \\
\hline Katsarolis et al (2009) & Greece & $1.4 \%$ \\
\hline
\end{tabular}

Ciprofloxacin resistance (fluoroquinolone): Ciprofloxacin resistance rate among all the isolates was $9.4 \%$, three and two of which, fell into the oxacillin resistant and sensitive groups respectively. Although fluoroquinolone resistance had not been tested in many studies in the past, testing has become common in the recent ones.Comparison with other studies 
Indian scenario

\begin{tabular}{|l|l|l|}
\hline Study & Place & Ciprofloxacin resistance rate \\
\hline Present & Bangalore & $9.4 \%$ \\
\hline ANSORP (2001) & Vellore & Not included \\
\hline
\end{tabular}

International scenario

\begin{tabular}{|l|l|l|}
\hline Study & Country & Ciprofloxacin resistance rate \\
\hline Katsarolis et al (2009) & Greece & $4 \%$ \\
\hline Kandakai YT et al. (2009) & Nigeria & $10.81 \%$ \\
\hline
\end{tabular}

MDRs Multidrug resistance rate was noted to be $18.9 \%$ among all the isolates and was similar to the pattern shown by a study done in Nigeria (21\%) [28]. It was 55.6\% among the penicillin resistant and $11.4 \%$ among the penicillin sensitive strains. While the ANSORP studies recorded much lower rate of MDR strains, majority of the other studies have shown increasing prevalence of MDRs.

Storage of pneumococcal isolates: The isolates were preserved in Skimmed milk, Trypticase soy, Glucose, Glycerol (STGG) medium at $-20^{\circ} \mathrm{C}$ for about a year. However, only 25 out of 53 isolates could be recovered probably due to unavoidable circumstances of unscheduled power failures etc.,.

\section{Serogroup types are listed in the Table 5, with pending further analysis.}

CONCLUSION: Pneumococcal carriage among children below five years in the urban set-up of Bangalore in this study is similar to that was found in many other studies.

Penicillin resistance among the isolates is of the intermediate level similar to the Indian scenario that may be because of the presence of 'Indian-strains' among S. pneumoniae. However, in the case of isolates those cause meningitis, even the penicillin intermediate resistance category falls into resistant group according to the CLSI-2008 guidelines. All the isolates in this study fall into resistant category in case they cause meningitis. But, if they cause invasive diseases other than meningitis, they will be considered sensitive.

Resistance to co-trimoxazole has reached its maximum and it should no longer be recommended for the management of pneumococcal diseases for quite some time. Extended spectrum cefalosporins, macrolides, and fluoroquinolones have shown good susceptibility patterns and can be used for recommended invasive diseases.

Routine screening for antibiotic susceptibility by oxacillin disc, judicious use of antibiotics, continued surveillance by keeping track of susceptibility patterns and attention to pneumococcal vaccination are advocated to inhibit the constant increase in resistance in pneumococci. Furthermore, serotyping pneumococcal isolates will help in formulating appropriate vaccine strategies and better control of pneumococcal diseases.

ACKNOWLEDGMENTS: We sincerely thank Prof., Dr. K. L. Ravikumar for his kind support and encouragement during the course of the study. 


\section{REFERENCES:}

1. Goyal R, Singh NP, Kaur M, Talwar V. Antimicrobial resistance in invasive and colonizing Streptococcus pneumoniae in north India. Indian Journal of Medical Microbiology 2007; 25(3): 256-9.

2. Lee NY, Song JH, Kim S, Peck RK, Ahn KM, Lee SI, et al. Carriage of Antibiotic-Resistant Pneumococci among Asian Children: A multinational Surveillance by the Asian Network for Surveillance of Resistant Pathogens (ANSORP). Clin Infect Dis 2001; 32: 1463-9.

3. Song JH, Lee NY, Ichiyama S, Yoshida R, Hirakata Y, Fu W, et al. Spread of drug resistant Streptococcus pneumoniae in Asian countries: Asian network for surveillance of resistant pathogens (ANSORP) study. Clin Infect Dis 1999; 28: 1206-11.

4. Winn WC Jr., Allen SD, Janda WM, Koneman EW, Procop GW, Schreckenberger PC, Woods GL, editors, Gram-Positive Cocci, Part 2: Streptococci, Enterococci, and the 'Streptococci-Like' Bacteria , Koneman's Color Atlas and Textbook of Diagnositc Microbiology, Lippincott Williams \& Wilkins, 2006: 689-93.

5. Musher DM. Pneumococcal Infections. Kasper DL, Braunwald E, Fauci AS, Hauser SL, Longo DL, Jameson JL, editors, Harrison's Principles of Internal Medicine, McGraw- Hill, 2008 (vol 1): 865-872.

6. Klugman KP, Friedland IR. Antibiotic-resistant pneumococci in pediatric disease. Microb Drug Resist 1995; 1:5-8.

7. Appelbaum PC. Resistance among Streptococcus pneumoniae: Implications for drug selection. Clin Infect Dis 2002; 34:1613-20.

8. Kanungo R, D’Lima D, Rajalakshmi B, Kumar A, Badrinath S. Emerging antibiotic resistant pneumococci in invasive infections in south India: Need for monitoring. Indian J Pharmacol 2002; 34:38-43.

9. Gray BM, Dillon HC. Epidemiological studies of Streptococcus pneumoniae in infants: antibody to types 3, 6, 14, and 23 in the first two years of life. J Infect Dis 1988; 158:94855.

10. Arason VA, Kristinsson KG, Sigurdsson JA, Stefansdottir G, Molstad S, Gudmundsson S. Do antimicrobials increase the carriage rate of penicillin-resistant pneumococci in children? Cross sectional prevalence study. BMJ 1996; 313:387-91.

11. Kaijalainen T, Identification of Streptococcus pneumoniae. National Public Health Insitute. A 11/2006. URL: http://www.ktl.fi/portal/4043, accessed July 5 2008.

12. Kilian M. Streptococcus and Lactococcus. Balows A, Duerden B, Collier L, Sussman M, editors, Topley and Wilson's Microbiology and Microbial Infections, ARNOLD, 1998 (vol 2): 633-667.

13. Abramson AS, and Overturf GD. Streptococcus pneumoniae (Pneumococcus). Kleigman RM, Behrman RE, Jenson HB, Stanton BF, editors, Nelson Text Book of Pediatrics, Saunders, 2007 (vol1): 1130-1135.

14. French N, and Gilks C. Pneumococcal disease. Cook GC, Zumla A, editors, Manson's tropical diseases, Saunders, 2003: 963-977.

15. O'Brien KL, Nohynek H. Report from a WHO Working Group: standard method for detecting upper respiratory carriage of Streptococcus pneumoniae. Pediatr Infect Dis J 2003; 22:e1-11.

16. Sleeman KL, Griffiths D, Shackley F, Diggle L, Gupta S, Maiden MC, et al. Capsular Serotype Specific Attack Rates and Duration of Carriage of Streptococcus pneumoniae in a Population of Children. JID 2006; 194: 682-88. 
17. Forbes BA, Sahm DF, Weissfeld AS. Role of microscopy, Bailey and Scott's Diagnostic Microbiology, Mosby, 2007: 81-82.

18. Winn WC Jr., Allen SD, Janda WM, Koneman EW, Procop GW, Schreckenberger PC, Woods GL, editors, Antimicrobial Susceptibility Testing, Koneman's Color Atlas and Textbook of Diagnositc Microbiology, Lippincott Williams \& Wilkins, 2006: 1009-11.

19. Lalitha MK, Manual on Antimicrobial Susceptibility Testing. Indian Journal of Medical Microbiology. URL: http://www.ijmm.org, accessed on July $13^{\text {th }} 2007$.

20. National committee for clinical laboratory standards. Performance standard for antimicrobial susceptibility testing. Eighth informational supplement, Wayne, PA: PA: National committee for clinical laboratory NCCLS document M 100-58.

21. AB BIODISK. Etest Technical Manual: Pneumococci, 2008; M0000448. URL: http://www.abbiodisk.com, accessed on July $20^{\text {th }} 2008$.

22. Huebner RE, Wasas A, Mushi A Mazhani L Klugman K. Nasopharyngeal carriage and antimicrobial resistance in isolates of Streptococcus pneumoniae and Haemophilus influenzae type b in children under 5 years of age in Botswana. Int J Infect Dis. 1998 JulSep; 3(1):18-25.

23. Samore MH, Magill MK, Alder SC, Severina E, Boer LM, Lyon JL, et al. High Rates of Multiple Antibiotic Resistance in Streptococcus pneumoniae From Healthy Children Living in Isolated Rural Communities: Association With Cephalosporin Use and Intrafamilial Transmission. Pediatrics 2001; 108: 856-865.

24. Jie LJ, Lin Y, Sangjie YU, Yonghong Y. Nasal carriage of Streptococcus pneumoniae in children in Beijing. Chin Med J 2001; 114 (11): 1196-1200.

25. Lo WT, Wang CC, Yu Cm, Chu ML. Rate of nasopharyngeal carriage, antimicrobial resistance and serotype of Streptococcus pneumoniae among children in northern Taiwan. J Microbiol Immunol Infect 2003; 36: 175-181.

26. Saha SK, Baqui AH, Darmstadt GL, Ruhulamin M, Hanif M, Arifeen SE, et al. Comparison of Antibiotic Resistance and Serotype Composition of Carriage and Invasive Pneumococci among Bangladeshi Children: Implications for Treatment Policy and Vaccine Formulation. JCM 2003; 41(12): 5582-5587.

27. Katsarolis I, Poulakou G, Analitis A, Matthaiopoulou I, Roilides E, Antachopoulos C, et al. Risk factors for nasopharyngeal carriage of drug-resistant Streptococcus pneumoniae: data from a nation-wide surveillance study in Greece. BMC Infectious Diseases 2009, 9:120.

28. Kandakai-Olukemi YT, Dido MS. Antimicrobial resistant profile of Streptococcus pneumoniae isolated from the nasopharynx of secondary school students in Jos, Nigeria. Ann Afr Med 2009;8:10-3

29. Clinical and Laboratory Standards Institute. Performance standards for antimicrobial susceptibility testing; eighteenth informational supplement. CLSI document M100-S18. Wayne, PA: Clinical and Laboratory Standards Institute; 2008.

30. Sherchand JB, Joshi AR, Gauchan P, Amatya J. Distribution of Serotypes and Antimicrobial Resistance of Streptococcus Pneumoniae in a Children's Hospital in Nepal. J Nepal Paediatr.Soc 2008; 28 (2): 45-8. 


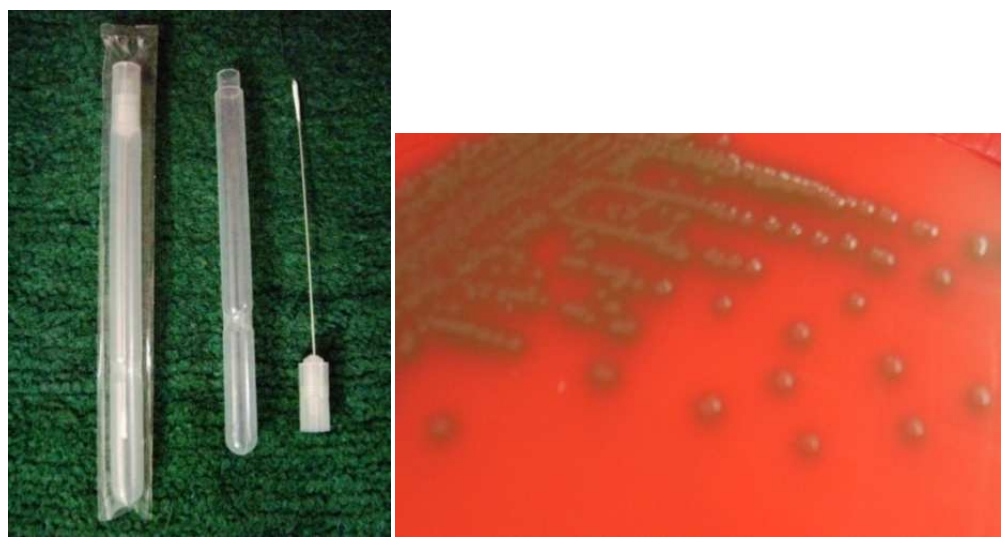

Fig.1: Pediatric (1mm) cotton tipped Fig.2: $\alpha$-lytic glistening draughtsman colonies on 5 nasopharyngeal swab. $\%$ sheep BA.
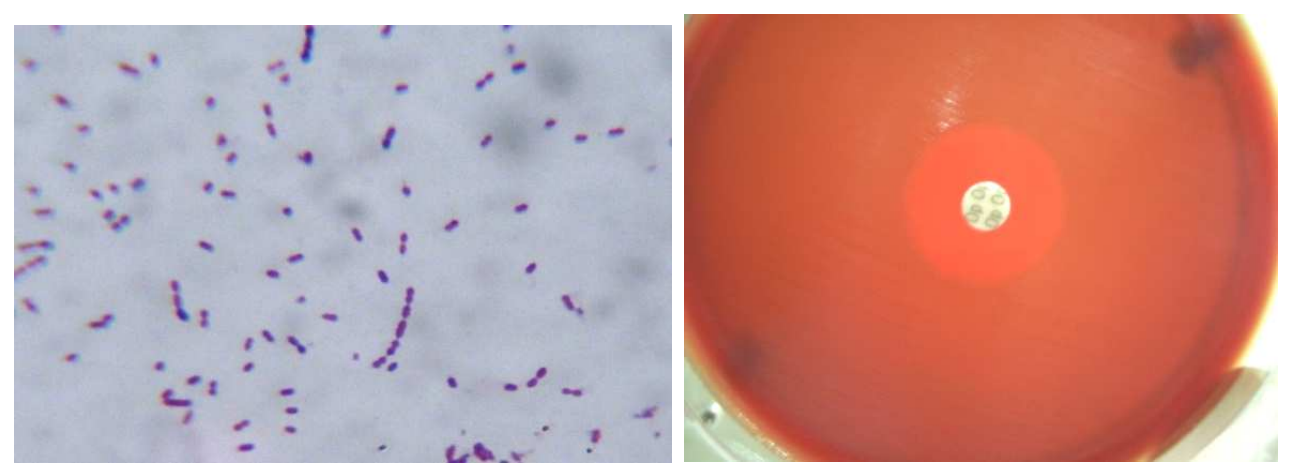

Fig.3: Gram positive lanceolate diplococci Fig.4: Optochin sensitivity test showing 'sensitive'

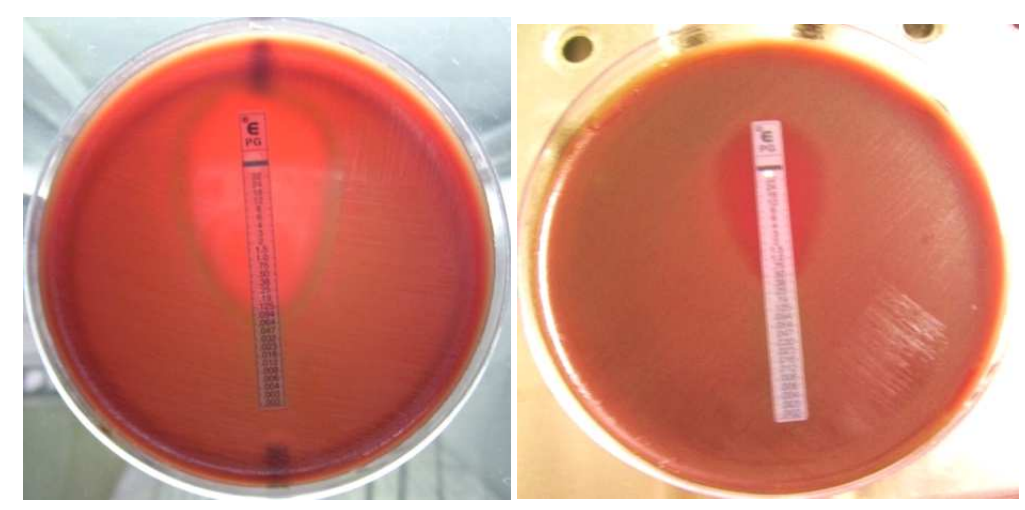

Fig.5: Penicillin MIC by E test showing 'penicillin sensitivity' and'intermediate resistance'. 

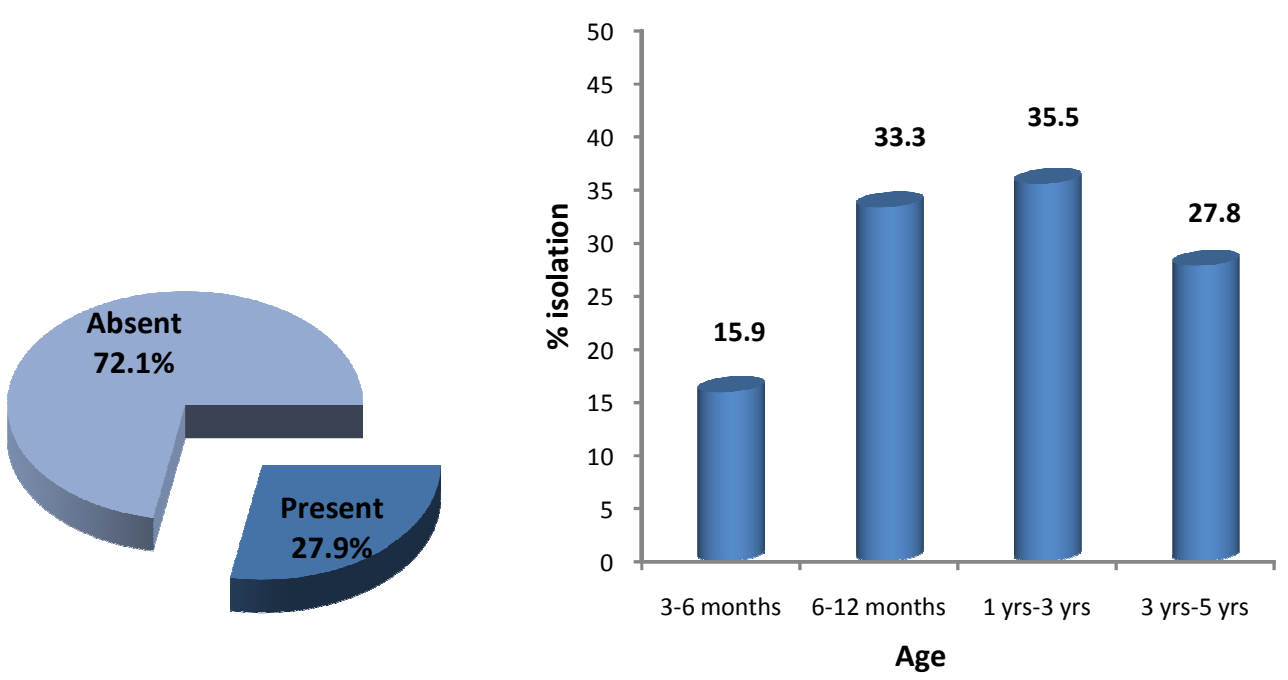

Graph 1: Pneumococcal carriage rate Graph 2: Age distribution and percentage of pneumococcal isolation
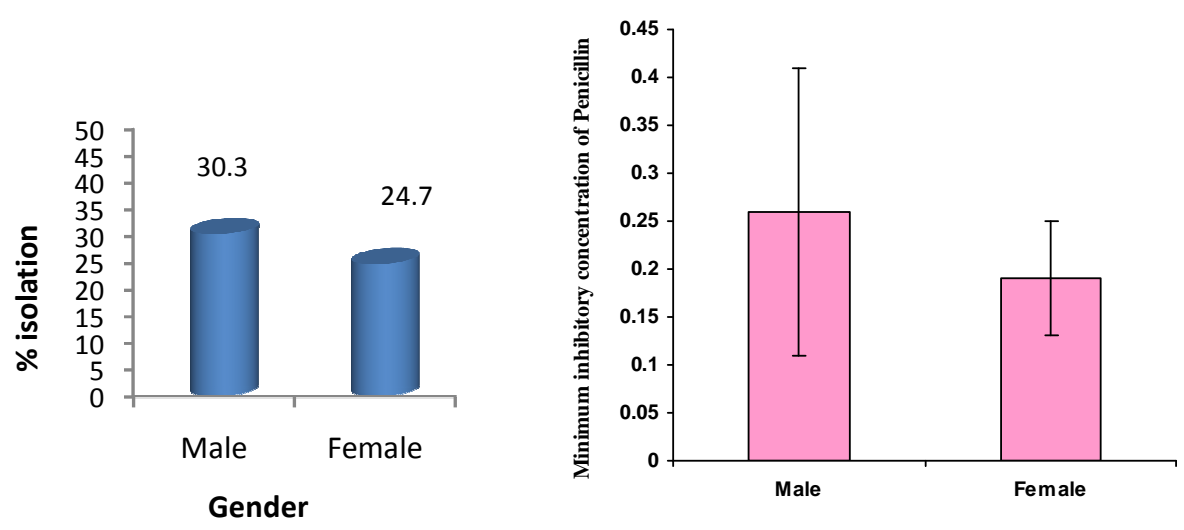

Graph 3: Gender distribution and percentage of Graph 4: MICs of penicillin in the pneumococcal isolation male and the female. 